\title{
The Physical and Chemical Properties of Hemp Fiber Prepared by Alkaline Pectinase-Xylanase System
}

\section{Shuyuan Zhao}

Donghua University

\section{Zhihui Qin}

Donghua University College of Textiles

\section{Ruiyun Zhang}

Donghua University College of Textiles

\section{Naiqiang Li}

Donghua University

Liu Liu ( $\sim$ liuliu@dhu.edu.cn )

Donghua University

Jianyong Yu

Donghua University

\section{Miaolei Xing}

Tiangong University

\section{Yongshuai Qu}

Donghua University

\section{Research Article}

Keywords: hemp fiber, degumming, alkaline xylanase, alkaline pectinase

Posted Date: July 14th, 2021

DOI: https://doi.org/10.21203/rs.3.rs-451112/v1

License: (c) (1) This work is licensed under a Creative Commons Attribution 4.0 International License. Read Full License 


\section{The physical and chemical properties of hemp fiber prepared by alkaline pectinase-xylanase system}

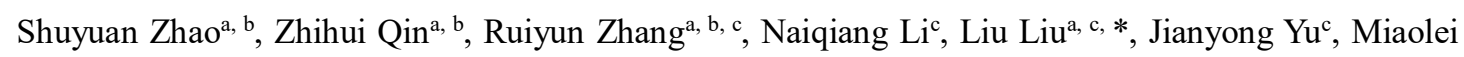
Jing $^{\mathrm{d}}$, Yongshuai $\mathrm{Qu}^{\mathrm{a}, \mathrm{b}}$

${ }^{a}$ Key Laboratory of Textile Science and Technology, Ministry of Education

${ }^{b}$ College of Textiles, Donghua University, Shanghai 201620, China

${ }^{c}$ Innovation Center for Textile Science and Technology, Donghua University, Shanghai 201620, China

${ }^{d}$ School of Textile Science and Engineering, Tiangong University, Tianjin 300387, China

${ }^{*}$ Corresponding author

E-mail: liuliu@dhu.edu.cn

\section{Abstract:}

Degumming is the vital and critical step in the preparation of hemp fiber for textile application. However, the traditional chemical degumming processes use large amounts of harmful chemicals, especially strong alkalis, which have caused severe challenges to the environment. The reaction conditions of alkaline pectinase and alkaline pectinase were studied in this research, and the alkaline pectinase-xylanase system was successfully applied to the degumming of hemp fibers at mild conditions $\left(\mathrm{T}=55{ }^{\circ} \mathrm{C}\right.$ and $\left.\mathrm{pH}=8.0\right)$ without strong alkali. A comparative analysis of hemp fibers treated under different conditions showed that the gum removal ratio could reach about $50 \%$ within $5.5 \mathrm{~h}$ of alkaline pectin-xylanase system degumming, making fiber smoother and stronger. After alkaline pectin-xylanase system treatment $\left(0.6 \mathrm{~g}\right.$ pectinase, $0.3 \mathrm{~g}$ xylanase, $\left.55^{\circ} \mathrm{C}, \mathrm{pH} 8.0,5.5 \mathrm{~h}\right)$, the removal ratio of pectin and hemicellulose reached $75 \%$ and $40 \%$, respectively. And linear density and tenacity of the fiber was 17.4 dtex and $5.62 \mathrm{cN} /$ dtex, respectively. SEM, FT-IR and XRD analysis furthermore demonstrated the excellent effects of the proposed process. The degumming fiber had better water retention performance (513\%) and moisture sorption ( $8.9 \%)$, which has more excellent application prospects in the textile industry. Moreover, the method abandons the use of acid and alkali and can provide an eco-friendly degumming process for hemp fiber.

Keywords: hemp fiber, degumming, alkaline xylanase, alkaline pectinase 


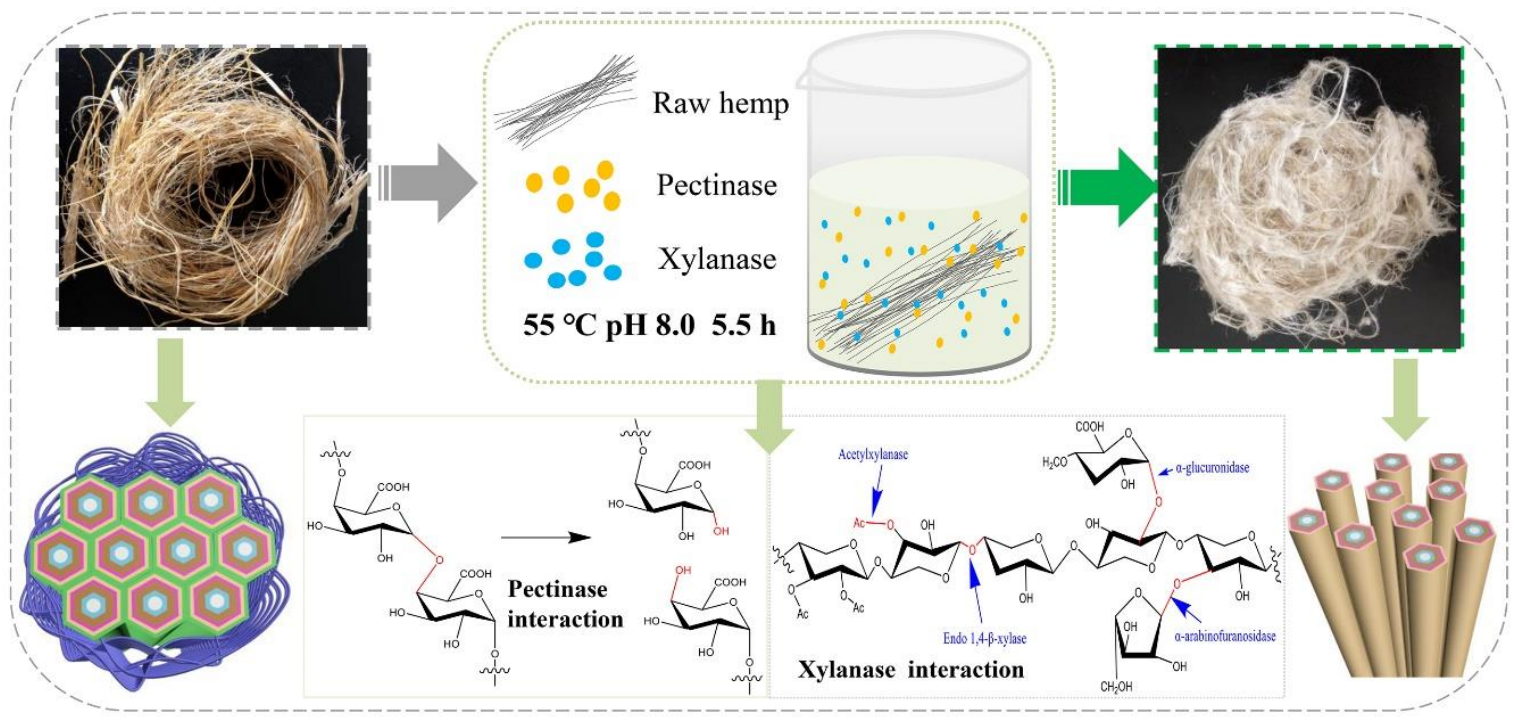

Abstract graph

\section{Introduction}

Nowadays, serious environmental issues have attracted increasing global attention, such as water pollution, energy consumption. Approximately $22 \%$ of global yearly freshwater consumed by the manufacturing industries, which produces large amounts of wastewater (Islam et al. 2019). In the manufacturing industries, the textile industry is considered one of the most severe environmental pollution industries due to extensive use of hazardous chemicals and high consumption of water and energy, especially the bast fibers textile industries (Chen et al. 2021; Jena et al. 2015). Therefore, green degumming technology is an important strategy to promote the sustainability of bast textile industry.

Hemp, which originated from central Asia, is most likely the oldest cultivated fiber plant. Scientists have utilize advanced technologies to cultivate non-toxic or low-toxic hemp, which has been planted on a large scale in many places, such as China, France and the United States (Batog et al. 2011; Ranalli et al. 2004; Schäfer et al. 2006). Furthermore, as a recyclable textile fiber resource, hemp has many excellent characteristics, such as good tensile strength, high moisture absorption and quick-drying, excellent antibacterial properties and potential sustainability and biodegradability, which make hemp fiber have huge application potential in the textile industry, and meanwhile, it is irreplaceable among natural fibers (Liu et al. 2019; Milanovic et al. 2012; Wang et al. 2003). However, raw hemp contains a large amount of non-cellulose compositions, such as pectin, lignin, and hemicellulose, which make hemp fiber coarse and weak, limiting the development and application in high-value textile and composite materials (Kozlowski et al. 2006; Zhang et al. 2013b; Zheng et al. 1988). Degumming is the 
dominant step in preparing hemp fiber for textile application (Jinqiu et al. 2010), but certain noncellulose materials should be retained to make hemp fiber suitable for a further spinning (Fan et al. 2015; Liu et al. 2019). However, the traditional chemical degumming with strong acid and hazardous alkali required high energy inputs and produced serious environmental pollution (Meng et al. 2019; Meng et al. 2018). In addition, the effect of the organic degumming process was approximate to that of chemical degumming. However, the organic degumming process still required high temperature, high reagent cost, high energy consumption, and subsequent solvent recovery was a new problem $(\mathrm{Qu}$ et al. 2020a; Qu et al. 2020b; Qu et al. 2020c). Therefore, it is urgent and essential to call for the development of clean, eco-friendly, effective, water and energy conservation degumming or pretreatment processes for hemp fibers.

Alternatively, enzymes degumming methods have received widespread attention because enzymes can effectively degrade substrates and reduce pollution (Yeping et al. 2019a). At present, there are many studies on the use of a combination of multiple enzymes or biochemical processes for raw hemp degumming. Fang et al. (Fang et al. 2017) utilized pectinase to pre-treat raw hemp, used strong alkali for chemical degumming, and finally bleached the fiber. Although the consumption of strong alkali chemicals was reduced, the process was too long and complex. The main reason for the unstable effect of enzyme degumming was that the entanglement of the non-cellulose composition prevented enzymes from approaching the active site, thereby reducing the degumming effect (Mohanty et al. 2000; Mwaikambo et al. 2002). Xiang et al. (Yeping et al. 2019a) used TEMPO, laccase and hemicellulase to treat raw hemp, but this paper only studied the degumming effects in acidic environments. However, there are few reports on the enzymes degumming of hemp in alkaline environments.

Pectin binds between single fiber cells and entangles with hemicellulose and lignin to form fiber bonding points, making hemp fibers into bundles of fibers in the hemp bast (Sadrmanesh et al. 2019). Pectinase can effectively hydrolyze the pectin material among the fibers, initially realize the splitting of the fiber bundles, and provide access channels for other enzymes to enter the fiber bast(Pakarinen et al. 2012; Valladares Juárez et al. 2009). As a green degumming biocatalyst, alkaline pectinase has excellent potential to replace the traditional alkaline high-temperature cooking process in the textile industry. Alkaline pectinase degumming can reduce energy consumption and alkali dosage. This process requires less water and energy and produces less environmental pollution(Basu et al. 2009; Kozlowski et al. 2006). However, pectinase degumming still has low enzyme activity, long time-consuming, and unstable quality 
of the prepared fiber. In addition, hemicellulose is interwoven with pectin to bond the fibers together (Khalili et al. 2002), and xylan is the main component in hemicellulose (Li et al. 2021). The removal of hemicellulose is essential for the degumming process, and xylanase can effectively hydrolyze xylan to remove hemicellulose, which has a significant contribution to fiber separation. In summary, it is necessary to study the effects of alkaline pectinase and alkaline xylanase on hemp degumming.

Based on the hydrolysis effect of alkaline pectinase and alkaline xylanase in removing non-cellulose substances, this work was to provide an eco-friendly degumming process for hemp degumming. In this study, parameters such as the dosage and time of alkaline pectinase and alkaline xylanase were studied, and the synergistic effect between the two biological enzymes was analyzed. Furthermore, microstructure and surface morphology were analyzed by scanning electron microscopy (SEM), Fourier transform infrared spectroscopy (FT-IR) and X-ray diffraction (XRD). Moreover, the mechanical and moisture absorption properties of the fiber were tested to assess the fiber quality and potential use. The alkaline pectinase-xylanase system provided a green process for the preparation of hemp fiber, and this study can provide a reference for the degumming of other bast fibers.

\section{Experimental details}

\subsection{Materials and chemicals}

Raw hemp used in this research was cultivated from Heilongjiang province, China. Alkaline xylanase (activity: 85,000 U/g) was obtained from Shandong Sukahan Biological Technology Co., Ltd (Qingdao City, Shandong province, China). Alkaline pectinase (activity: 15,000 U/g) was provided by Shandong Qingdao KDN Biological Technology Co., Ltd (Qingdao City, Shandong province, China). Sodium hydroxide $(\mathrm{NaOH})$, ammonium oxalate $\left(\left(\mathrm{NH}_{4}\right)_{2} \mathrm{C}_{2} \mathrm{O}_{4}\right)$, absolute ethanol $\left(\mathrm{C}_{2} \mathrm{H}_{6} \mathrm{O}\right)$, benzene $\left(\mathrm{C}_{6} \mathrm{H}_{6}\right)$, sodium dihydrogen phosphate $\left(\mathrm{NaH}_{2} \mathrm{PO}_{4}\right)$, disodium hydrogen phosphate $\left(\mathrm{Na}_{2} \mathrm{HPO}_{4}\right)$ and sulfuric acid $\left(\mathrm{H}_{2} \mathrm{SO}_{4}\right)$ were purchased from Sinopharm Chemical Reagent Co., Ltd (Shanghai, China). All used chemicals obtained from commercial sources were of analytical reagent grade without further purification. And Deionized water was used as a solvent to prepare the solution.

\subsection{Preparation of degummed hemp fibers}

Raw hemp was dried at $50{ }^{\circ} \mathrm{C}$ in a blast oven for 24 hours to obtain a constant humidity content before degumming treatments. According to the applicable work conditions of two alkaline enzymes (alkaline xylanase: $\mathrm{T}=45-60{ }^{\circ} \mathrm{C}, \mathrm{pH}=6.5-9.0$; alkaline pectinase: $\mathrm{T}=40-55{ }^{\circ} \mathrm{C}, \mathrm{pH}=6.0-8.5$ ), the degumming conditions were selected at a temperature of $55^{\circ} \mathrm{C}$ and a $\mathrm{pH}$ of 8.0. The $\mathrm{pH}$ value of the 

were immersed entirely into the degumming solution, and the bath ratio was 1:20. During the reactive process, the solutions were stirred for 1 minute per hour. The degummed fibers were washed completely with deionized water and then dried at $106{ }^{\circ} \mathrm{C}$ in a blast oven for 3 hours. The experimental conditions

113 of multiple control groups were set up to study the dosage of enzymes and reaction time. The detailed 114 experimental conditions were shown in Table 1.

115 Table 1 Control groups: the dosages of alkaline pectinase and alkaline xylanase, and reaction time

\begin{tabular}{|c|c|c|c|c|c|c|c|c|c|c|c|c|}
\hline $\begin{array}{l}\text { Control } \\
\text { groups }\end{array}$ & \multicolumn{4}{|c|}{$\begin{array}{l}\text { Different dosage of } \\
\text { alkaline pectinase }\end{array}$} & \multicolumn{4}{|c|}{$\begin{array}{l}\text { Different dosage of } \\
\text { alkaline xylanase }\end{array}$} & \multicolumn{4}{|c|}{ Different reaction time } \\
\hline pectinase (g) & 0.3 & 0.6 & 0.9 & 1.2 & 0 & 0 & 0 & 0 & 0.6 & 0.6 & 0.6 & 0.6 \\
\hline $\begin{array}{c}\text { Alkaline } \\
\text { xylanase (g) }\end{array}$ & 0 & 0 & 0 & 0 & 0.1 & 0.3 & 0.5 & 0.7 & 0.3 & 0.3 & 0.3 & 0.3 \\
\hline $\begin{array}{c}\text { Reaction time } \\
\text { (h) }\end{array}$ & 7.5 & 7.5 & 7.5 & 7.5 & 7.5 & 7.5 & 7.5 & 7.5 & 3.5 & 5.5 & 7.5 & 9.5 \\
\hline
\end{tabular}

Other conditions

$\mathrm{pH}=8.00 .2 \mathrm{M}$ phosphate buffer solution, bath ratio $1: 20,55^{\circ} \mathrm{C}$

116 To further study whether there was a synergistic effect between alkaline pectinase and alkaline 117 xylanase in the degumming process, raw hemp fibers were immersed entirely into the degumming 118 solution for 5.5 hours. During the degumming process, the solutions were stirred for 1 minute per hour.

119 The degummed fibers were washed thoroughly with deionized water and then dried at $106^{\circ} \mathrm{C}$ in a blast oven for 3 hours. The components of solutions were presented in Table 2.

Table 2 The different reagents formulation solution

\begin{tabular}{cc}
\hline Sample & Solvents \\
\hline $1 \#$ & $/$ \\
$2 \#$ & Buffer solution \\
$4 \#$ & Alkaline pectinase $0.6 \mathrm{~g}$ in buffer solution \\
$5 \#$ & Alkaline xylanase $0.3 \mathrm{~g}$ in buffer solution \\
\hline
\end{tabular}

\subsection{Fourier transform infrared spectroscopy (FTIR)}

123 FT-IR analysis was used to determine the chemical groups in the treated hemp fiber. FT-IR spectra 
were recorded on a Nicolet 6700 spectrometer (Thermo Fisher Scientific, Waltham, USA) with a spectral resolution of $4 \mathrm{~cm}^{-1}$ and 30 scans, and the range was from 4000 to $600 \mathrm{~cm}^{-1}$. The baseline should be corrected and smoothed before further analysis.

\subsection{Scanning electron microscope (SEM)}

The morphologies of the hemp fibers were observed under a scanning electron microscope (SEM, VEGA 3, TESCAN Ltd., Czech Republic). After sticked on the sample stage, the samples were sputtered with a thin layer of gold. SEM was operating at $10 \mathrm{kV}, 20^{\circ} \mathrm{C}$ and relative humidity (RH) of $65 \%$.

\subsection{X-ray diffraction analysis (XRD)}

The XRD patterns were performed on a Rigaku diffractometer (D/MAX-2550 PC, Tokyo, Japan) equipped with $\mathrm{Cu}$ k $\alpha$ radiation at $40 \mathrm{kV}$ and $200 \mathrm{~mA}$. The patterns were recorded in the $2 \theta$ range of $5^{\circ}$ $\sim 60^{\circ}$ and a scan rate of $2^{\circ} \min ^{-1}$.

The crystallinity index (CrI) was calculated by the following method Eq. (1) (Nie et al. 2018):

$$
\operatorname{CrI}(\%)=\left(\frac{I_{200}-I_{a m}}{I_{200}}\right) \times 100
$$

CrI represents the relative degree of crystallinity, $\mathrm{I}_{200}$ is the maximum intensity of the (200) lattice diffraction at $2 \theta$ around $22.8^{\circ}$, and $\mathrm{I}_{a m}$ is the intensity of diffraction at $2 \theta$ around $18.6^{\circ}$ (El Achaby et al. 2018; Kassab et al. 2019).

\subsection{Chemical components analysis}

The chemical composition was tested according to the Chinese standard GB/T 5889-86. All experiments of each sample were performed separately in triplicate, and the result was the average of the experimental results of three samples. The standard deviation was controlled within $3 \%$ of the average value.

\subsection{Mechanical property tests}

All samples were conditioned in standard atmospheric conditions 24 hours before testing, and standard atmospheric condition was $20 \pm 2{ }^{\circ} \mathrm{C}$ and $\mathrm{RH}$ of $65 \pm 3 \%$. The breaking tenacity of fibers was tested by an XQ-1A fiber tensile tester (New Fiber Instrument, shanghai, China). The gauge length and drawing speed were kept at $20 \mathrm{~mm}$ and $20 \mathrm{~mm} / \mathrm{s}$, respectively. The linear density, tenacity, and breaking elongation were tested according to Chinese standards GB/T 18147.4 and GB/T 18147.5. The average value was obtained by using results from 100 specimens, and the linear density was calculated according to Eq. (2): 


$$
D_{d t}=10 \mathrm{G} / \mathrm{NL}
$$

$\mathrm{G}$ is the mass in grams of fiber, $\mathrm{n}$ is the fiber numbers, and $\mathrm{L}$ is cutting length $(20 \mathrm{~mm})$.

\subsection{Determination of moisture sorption and the water retention value}

Moisture sorption of hemp fibers was tested according to the standard method ASTM D 265476:1976. Degummed fibers were conditioned to a standard atmosphere $\left(20 \pm 2{ }^{\circ} \mathrm{C}, 65 \pm 2 \% \mathrm{RH}\right)$ for 24 hours. Moisture sorption was calculated as a weight percentage of absolute dry material, and it was an average value of three parallel tests. Standard centrifuge method ASTM D 2402-78:1978 was used to determine the water retention value of cellulose fibers, and the results were the average of three parallel determinations. The centrifuge speed (CT 14RD-II, Shanghai Tianmei Science and Technology Industry Co. Ltd) was about $400 \mathrm{rpm} / \mathrm{min}$.

\section{Results and discussion}

\subsection{The dosages of alkaline pectinase, alkaline xylanase, and reaction time}

Raw hemp was processed under different conditions, and appropriate experimental parameters were obtained by comprehensively analyzing the weight loss rate and the residual gum rate. The suitable amount of alkaline pectinase and alkaline xylanase was studied, respectively, and the results of control groups were shown in Figure 1 (a) and (b). As the usage of enzymes increased, the weight loss rate increased, and the residual gum rate decreased sharply. The residual gum rates of alkaline pectinase control group $(0.3 \mathrm{~g}, 0.6 \mathrm{~g}, 0.9 \mathrm{~g}$ and $1.2 \mathrm{~g})$ were $32.62 \%, 30.33 \%, 29.45 \%, 29.32 \%$, and the weight loss rate were $26.46 \%, 28.85 \%, 29.12 \%, 29.45 \%$, respectively. After alkaline pectinase treatment, the residual gum rate and weight loss rate had a little obvious change. Considering the content of pectin in the raw hemp component was less than $5 \%, 0.6 \mathrm{~g}$ alkaline pectinase could achieve the removal of pectin in the raw hemp. The residual gum rates corresponding to alkaline xylanase control group $(0.1 \mathrm{~g}, 0.3 \mathrm{~g}$, $0.5 \mathrm{~g}, 0.7 \mathrm{~g}$ ) were $28.35 \%, 26.23 \%, 24.86 \%, 21.41 \%$, and the weight loss rates were $26.25 \%, 35.78 \%$, $38.07 \%, 40.02 \%$, respectively. Xylanase mainly hydrolyzed the xylan in hemicellulose to achieve the purpose of removing hemicellulose. Hemicellulose played a vital role in maintaining the length of the process fiber. Although the $0.5 \mathrm{~g}$ and $0.7 \mathrm{~g}$ alkaline xylanase treatments performed well at a low residual gum rate, the weight loss rate increased greatly, and the fiber strength was seriously reduced. The dosage of $0.3 \mathrm{~g}$ xylanase had a lower residual gum rate, and could keep the fiber with a good length and strength. The reaction time of $3.5 \mathrm{~h}, 5.5 \mathrm{~h}, 7.5 \mathrm{~h}, 9.5 \mathrm{~h}$ was further studied, and the corresponding residual gum rate was $28.21 \%, 20.11 \%, 18.44 \%, 16.22 \%$, and the corresponding weight loss rate was $25.24 \%$, 
$36.56 \%, 44.74 \%, 47.42 \%$, respectively. There was no obvious change in the fiber after the $3.5 \mathrm{~h}$ treatment, while the fibers after the $7.5 \mathrm{~h}$ and $9.5 \mathrm{~h}$ treatments had a low residual gum rate, but the length was too short. Therefore, the conditions used in this study were: temperature $55^{\circ} \mathrm{C}, \mathrm{pH} 8.0$, time $5.5 \mathrm{~h}$, alkaline pectinase $0.6 \mathrm{~g}$, alkaline xylanase $0.3 \mathrm{~g}$. In this study, the synergy between alkaline pectinase and alkaline xylanase was further studied.
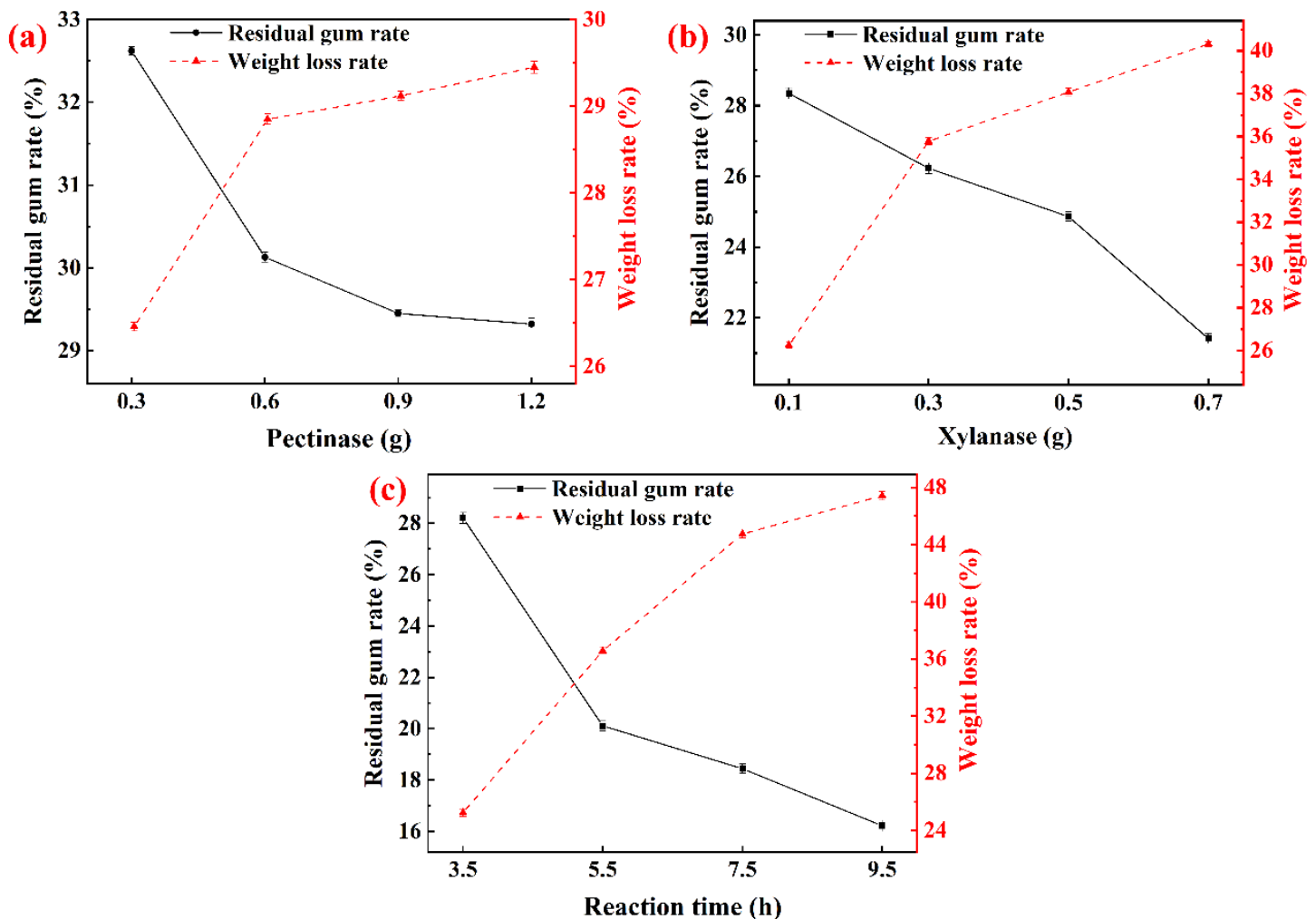

Fig 1. Residual gum rates and weight lose rates of fibers with different treatments: (a) alkaline pectinase control group: $0.3,0.6,0.9,1.2 \mathrm{~g}$, (b) alkaline xylanase control group: $0.1,0.3,0.5,0.7 \mathrm{~g}$, (c) reaction time control group: $3.5,5.5,7.5,9.5 \mathrm{~h}$

\subsection{Surface morphology of hemp fiber}

SEM micrographs of hemp fibers presented a clear view of degumming capability. Figure 2 showed the SEM images of raw hemp fiber and degummed fibers with different conditions. The raw hemp fibers had a rough and coarse surface with no fiber exposed (Fig. 2(a)). As seen from Fig. 2(b), hemp fibers treated only with buffer solution were insufficient to eliminate non-cellulose substrates, and there was no separation between fibers. The fibers treated with alkaline pectinase (Fig. 2(c)) and alkaline xylanase (Fig. 2(d)) respectively had various degrees of gums removal. The fiber surface was smooth and longitudinal cracks could be observed, which demonstrated that alkaline pectinase and alkaline xylanase had significant effects on hemp degumming. Specially treated with alkaline pectinase-xylanase (Fig. 



204
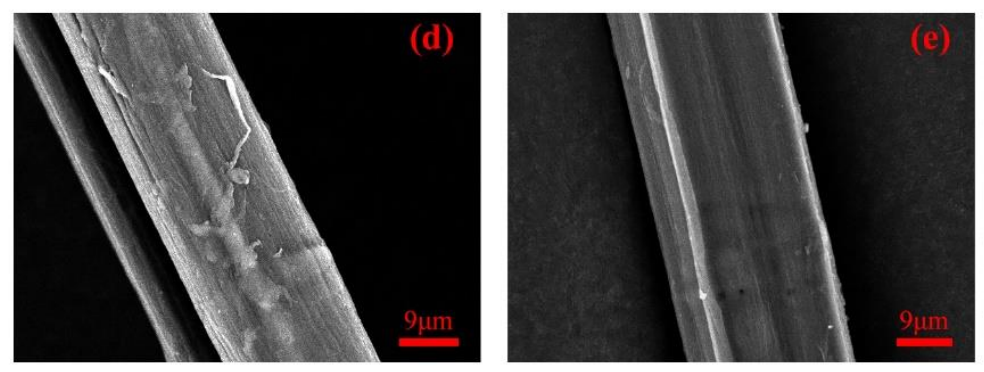

Fig 2. SEM images of hemp fiber. (a) raw hemp, (b)hemp treated with buffer solution, (c) hemp treated with alkaline pectinase solution, (d) hemp treated with alkaline xylanase solution, (e) hemp treated with alkaline pectinase-xylanase solution

\subsection{Chemical composition}

Hemp in the individual fiber state is unsuitable for spinning due to its low strength and short length (12-25 mm), which limited its further application (Liu et al. 2017). Researchers have proposed that part of the gum compositions should been retained to link single fiber as a technical fiber, which can get a certain length of the fiber bundle and be capable of spinning (Sadrmanesh et al. 2019). Chemical compositions of hemp fibers disposed of different treatments were presented in Table 3 and Figure 3. Compared with raw hemp or other treated process, the hemp fiber (5\#) treated with alkaline pectinasexylanase solution had the highest cellulose value of $79.41 \%$, indicating that it was sufficient to remove non-cellulose components. The removal rates of hemicellulose and pectin were $42 \%$ and $75 \%$, respectively. In Table 3 and Figure 3, it was similar that the changing trend of pectin and hemicellulose content both decreased simultaneously, which indicated that a variety of chemical bonds connected pectin and hemicellulose. They intertwined with each other and connected with cellulose intricately. Raw hemp (2\#) was treated with the buffer solution, and the pectin had been significantly reduced, indicating that part of the pectin could be dissolved in the buffer solution. As compared single biological enzyme 
treatment $(3 \#, 4 \#)$ and alkaline pectinase-xylanase treatment $(5 \#)$, it was found that the reduction of hemicellulose and pectin had changed significantly, which further implied the synergistic effect of pectinase and xylanase. In addition, there was a significant decrease in lignin content, which may be caused by the removal of the entangled lignin during the removal process of hemicellulose and pectin.

Table 3 Chemical composition in hemp fiber under different degumming methods

\begin{tabular}{ccccccc}
\hline & Cellulose & Hemicellulose & Water & Others \\
Sample & $(\%)$ & $(\%)$ & Lignin $(\%)$ & Soluble $(\%)$ & & $(\%)$ \\
\hline $1 \#$ & $62.32 \pm 0.17$ & $19.40 \pm 0.08$ & $9.09 \pm 0.16$ & $5.11 \pm 0.20$ & $4.08 \pm 0.18$ & $0.41 \pm 0.11$ \\
$2 \#$ & $67.16 \pm 0.11$ & $18.84 \pm 0.16$ & $8.77 \pm 0.08$ & $3.01 \pm 0.11$ & $2.22 \pm 0.16$ & $0.23 \pm 0.01$ \\
$3 \#$ & $69.51 \pm 0.31$ & $17.89 \pm 0.26$ & $8.57 \pm 0.19$ & $3.02 \pm 0.17$ & $1.01 \pm 0.06$ & $0.02 \pm 0.01$ \\
$4 \#$ & $73.41 \pm 0.26$ & $14.87 \pm 0.16$ & $7.71 \pm 0.17$ & $2.91 \pm 0.13$ & $1.20 \pm 0.07$ & $0.01 \pm 0.01$ \\
$5 \#$ & $79.41 \pm 0.25$ & $11.25 \pm 0.10$ & $6.00 \pm 0.13$ & $2.67 \pm 0.06$ & $1.02 \pm 0.11$ & $0.01 \pm 0.01$ \\
\hline
\end{tabular}

1\# raw hemp, 2\# hemp treated with buffer solution, 3\# hemp treated with alkaline pectinase solution, 4\# hemp treated with alkaline xylanase solution, $5 \#$ hemp treated with alkaline pectinase-xylanase solution

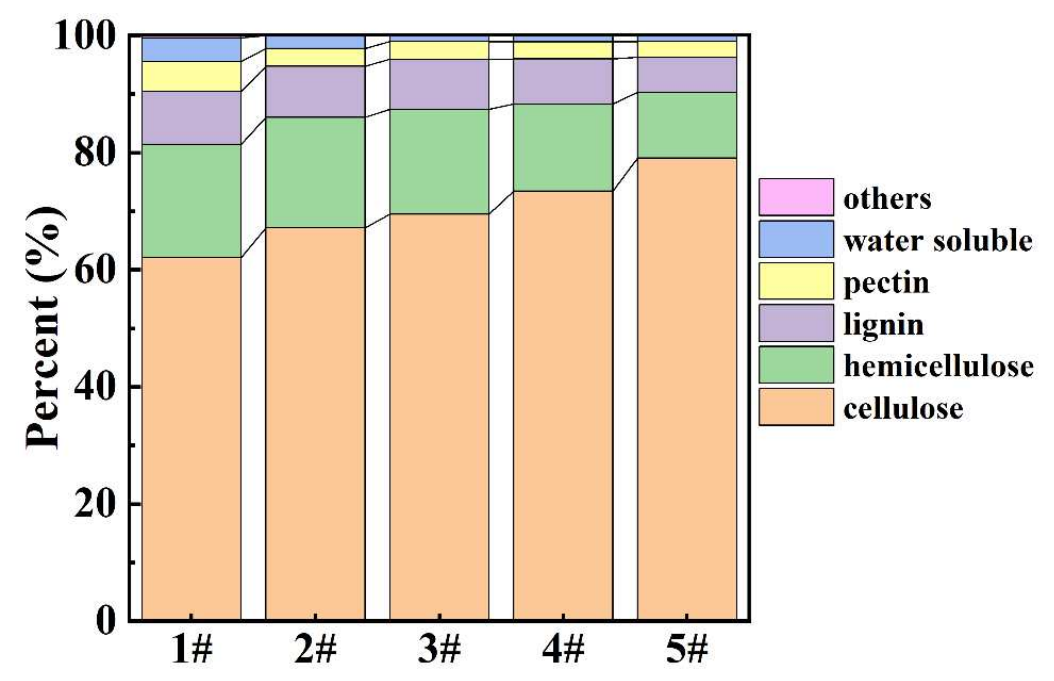

Fig 3. Chemical composition in hemp fiber: 1\# raw hemp, $2 \#$ hemp treated with buffer solution, $3 \#$ hemp treated with alkaline pectinase solution, $4 \#$ hemp treated with alkaline xylanase solution, 5\# hemp treated with alkaline pectinase-xylanase solution

\subsection{Chemical analysis (FT-IR)}

To further identify the changes in the chemical composition of hemp fiber prepared by various methods, infrared spectroscopy analysis was carried out to observe the distribution of the main chemical bonds in the hemp components, as shown in Figure 4. The main difference in infrared spectra was 
between 2000-650 $\mathrm{cm}^{-1}$ (Yeping et al. 2019b). Results showed that cellulose characteristic peaks of samples existed all samples, including cellulose $\mathrm{OH}$ in-plane deformation adsorption around $1335 \mathrm{~cm}^{-1}$, $\mathrm{O}-\mathrm{H}$ plane bending vibration adsorption around $1205 \mathrm{~cm}^{-1}, \mathrm{C}-\mathrm{O}-\mathrm{C}$ telescopic vibration adsorption around $1160 \mathrm{~cm}-1$, cellulose glucose ring $\mathrm{CO}$ ether bond stretching vibration adsorption around $1050 \mathrm{~cm}^{-1}, \mathrm{C}=\mathrm{O}$ telescopic vibration adsorption around $1030 \mathrm{~cm}^{-1}$ (Liu et al. 2019). After degumming with alkaline pectinase-xylanase solution, the intensities of these peaks increased obviously, which suggested the treatment have successfully removed gummy components and purified cellulose of hemp fiber. The treated fibers $(2 \#, 3 \#, 4 \#, 5 \#)$ exhibited strong absorption intensities, such as $\beta$-glycosidic bonds of carbohydrates around $896 \mathrm{~cm}^{-1}$ and the $\mathrm{O}-\mathrm{H}$ associative band of cellulose around $1110 \mathrm{~cm}^{-1}$. The intensity of peaks around $1510 \mathrm{~cm}^{-1}$, corresponding to aromatic ring vibration of lignin (Sain et al. 2006), decreased gradually, which was in good accordance with the reducing lignin demonstrated in Table 3. Besides, the intensity of $\mathrm{C}=\mathrm{O}$ stretching vibration from the esters of hemicellulose around $1732 \mathrm{~cm}^{-1}$ exhibited weaker with the alkaline pectinase-xylanase treated than raw hemp. This was related to the rapid decrease of xylan under the conditions of alkaline xylanase hydrolysis. From the FT-IR analysis, we can safely conclude that the alkaline pectinase-xylanase degumming process had a good effect on removing gummy substances in this study.

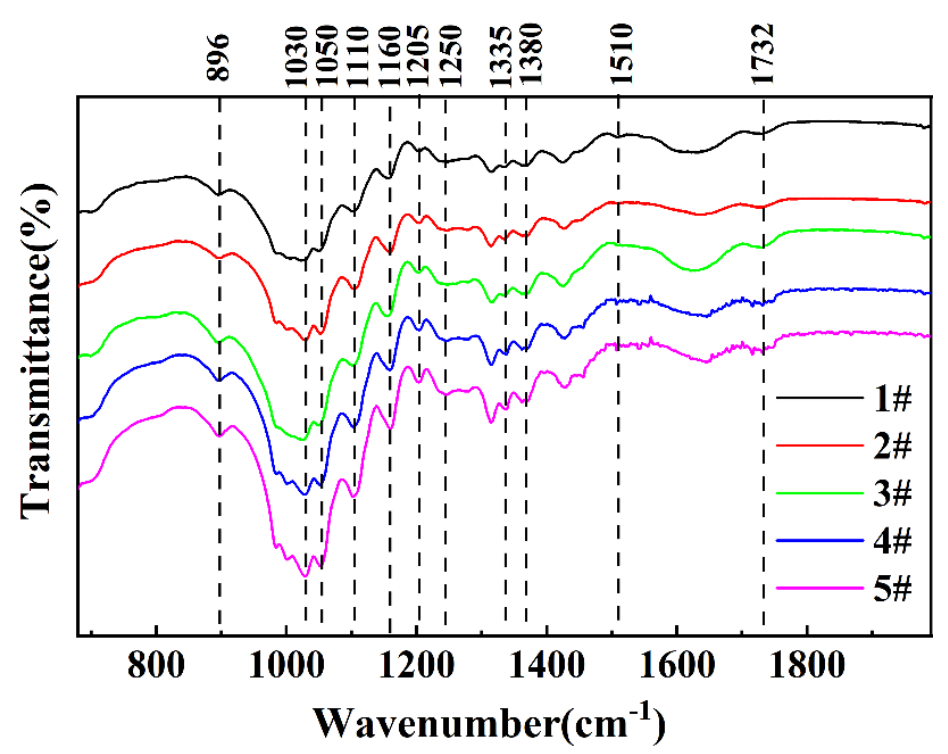

Fig 4. FT-IR spectra of hemp fiber: 1\# raw hemp, 2\# hemp treated with buffer solution, 3\# hemp treated with alkaline pectinase solution, $4 \#$ hemp treated with alkaline xylanase solution, $5 \#$ hemp treated with alkaline pectinase-xylanase solution

\subsection{Crystal structure analysis (XRD)}



curves presented a central crystalline peak for $2 \theta$ ranging between $22^{\circ}$ and $23^{\circ}$, which correspond to the (200) crystallographic plane family of cellulose I (Meng et al. 2019). The other peaks for $2 \theta$ presented between $14.8^{\circ}$ and $16.8^{\circ}$, corresponding to the (1-10) crystallographic plane family of cellulose II (French 2014). It was evident that there was no crystal structure transformation after treated in different ways. The crystallinity index (CrI) of hemp fibers showed in Figure 5(b). The CrI of raw hemp (1\#) was the lowest value of $54.17 \%$, and the $\mathrm{CrI}$ of other treated fibers had a drastic increase. This was related to the reduction of non-cellulose components. The CrI of fiber degummed with the alkaline pectinasexylanase system $(5 \#, 73.72 \%)$ was higher than that treated with alkaline pectinase $(3 \#, 68.42 \%)$ or alkaline xylanase $(4 \#, 70.18 \%)$. The main reason may be that pectin macromolecules were degraded under the action of alkaline pectinase, exposing more alkaline xylanase catalytic sites (Khalili et al. 2002). This accelerated the catalytic reaction of alkaline xylanase, and the degradation of hemicellulose macromolecules contributed to the liberation of pectin molecules, which in turn promoted the catalysis of alkaline pectinase (Pakarinen et al. 2012). The effect of alkaline pectinase and alkaline xylanase together increased the active centre of the reaction substrate, which improved the practical work of the two alkaline enzymes and promoted the degumming effect. This situation was consistent with the results of chemical composition analysis and SEM.
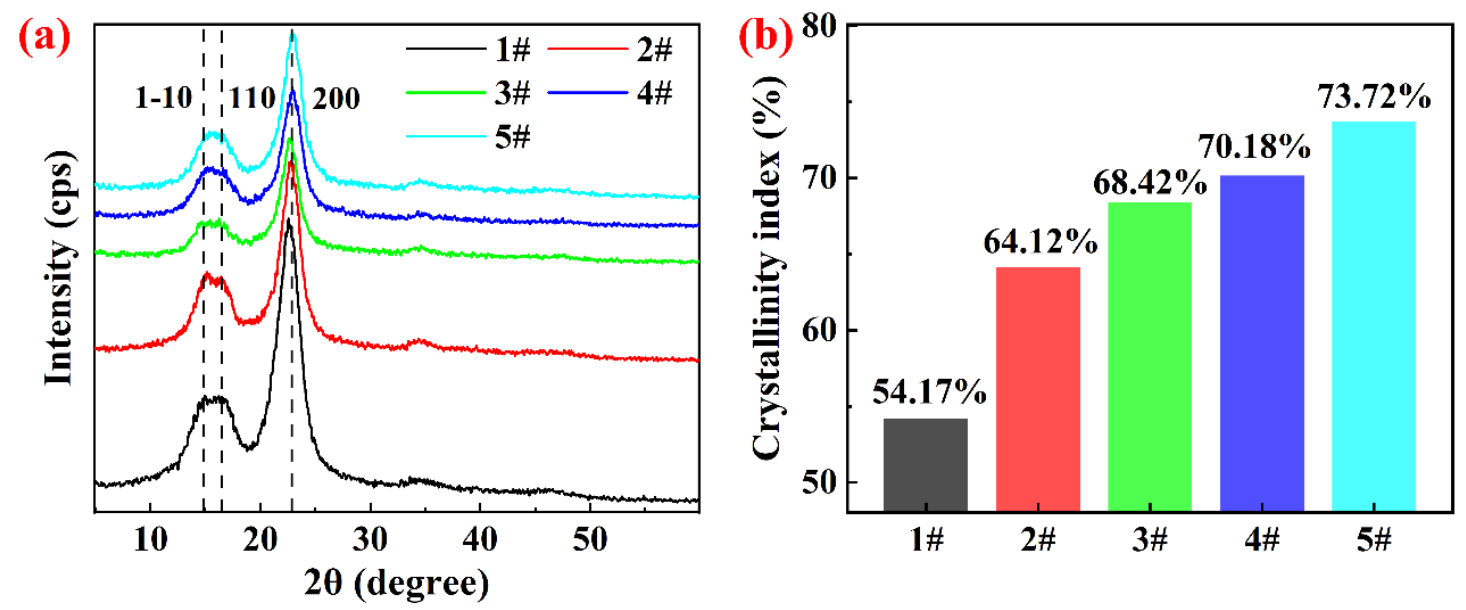

Fig 5. Crystalline analysis of hemp fiber. (a) X-ray diffraction curves of hemp fibers with different treatments, (b) the percent crystallinity index of hemp fibers with different treatments: 1\# raw hemp, 2\# hemp treated with buffer solution, $3 \#$ hemp treated with alkaline pectinase solution, $4 \#$ hemp treated with alkaline xylanase solution, $5 \#$ hemp treated with alkaline pectinase-xylanase solution 
Through the above characterization and analysis, hemp fiber structure directly affected the degumming effect of biological enzymes. Figure 6 depicted the structure diagram of hemp fiber and a schematic diagram of structural changes before and after degumming. Single fibers in a bundle were connected by a substance called middle lamella (Figure 6(a)), which was primarily composed of pectin and act as glue (Terzopoulou et al. 2015). Single fiber had two main components: primary wall and secondary wall (Figure 6(b)). These walls surrounded a small channel called a lumen, which was filled with protein and pectin. The primary wall was composed of a rigid framework of hemicellulose, pectin compounds and cellulose microfibrils in the glycoprotein network (Sadrmanesh et al. 2019). The secondary wall structure had three layers (S1-S3), composed of cellulose, hemicellulose and lignin, and S2 constituted most structure of the fibers (Zykwinska et al. 2008). The non-cellulosic polysaccharides had mainly two classes of structuring polysaccharides and matrix polysaccharides. Structuring polysaccharides, such as $\beta-1,4$ - glucomannans and $\beta-1,4$-xylans, constituted hemicelluloses and pectic $\beta$-1,4-galactans, and matrix polysaccharides contributed to the formation of pectin. (Gorshkova et al. 2006). Besides, the cohesion between microfibrils was reached by bonds between matrix polysaccharides and hemicelluloses and by hydrogen interactions between structuring polysaccharides and cellulose (Gorshkova et al. 2012; Nishiyama et al. 2003). In the degumming process, the raw hemp wrapped in gummy substances (Figure 6(c)) was preliminarily hydrolyzed by alkaline pectinase and alkaline xylanase. The residual cortical tissue was first removed, and the large bundle fibers were split into smaller bundle fibers. With the drastic decrease of gummy substances under the action of enzymes, the bundle fiber become finally finer fibers.
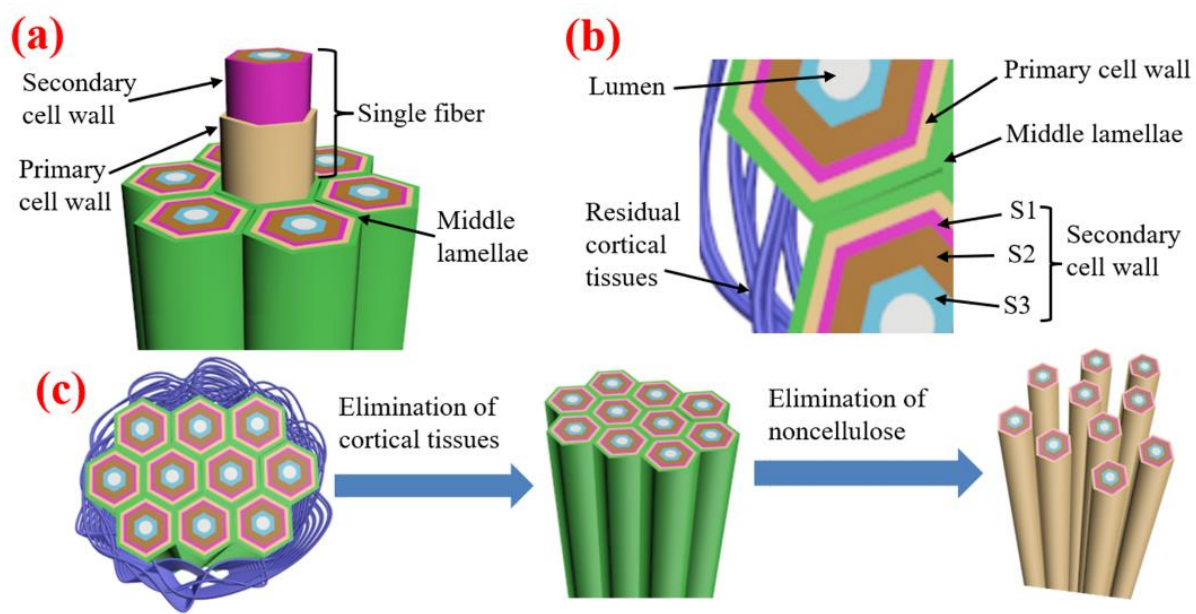

Fig 6. Schematic diagram of raw hemp fiber structure and structural change during degumming process: (a) fiber bundle structure in raw hemp, (b) structure of fiber, (c) changes of fiber structure before and after degumming process

In the process of degumming, biological enzymes have the characteristic of specific catalysis. The polymerization of galacturonic acid forms pectin substrate with different esterification degrees and $\alpha-1,4$ glycosidic bonds. According to the substrate and mode of action, pectinase can be divided into three types: pectinesterase, pectin lyase and pectin hydrolase (Gorshkova et al. 2012; Kashyap et al. 2001; Xiao et al. 2008). Figure 7 showed the interaction mode of the main pectinase. Pectin esterase (PE) can 
hydrolyze the methyl esters in pectin to produce pectic acid, which was soluble in water (Figure 7(a)), and it was particular to methyl esters in polygalacturonic acid. Methanol was split from the carboxyl group. Polygalacturoniase (Figure 7(b)) (pectate lyase PGL) cut off the pectic acid molecule $\alpha-1,4$ glycosides through trans elimination ( $\beta$ elimination method) to generate galacturonate with unsaturated bonds (Ma et al. 2016). The SEM morphology and composition analysis showed that alkaline pectinase could effectively catalyze pectin degradation and cause the splitting of fiber bundles.

(a)
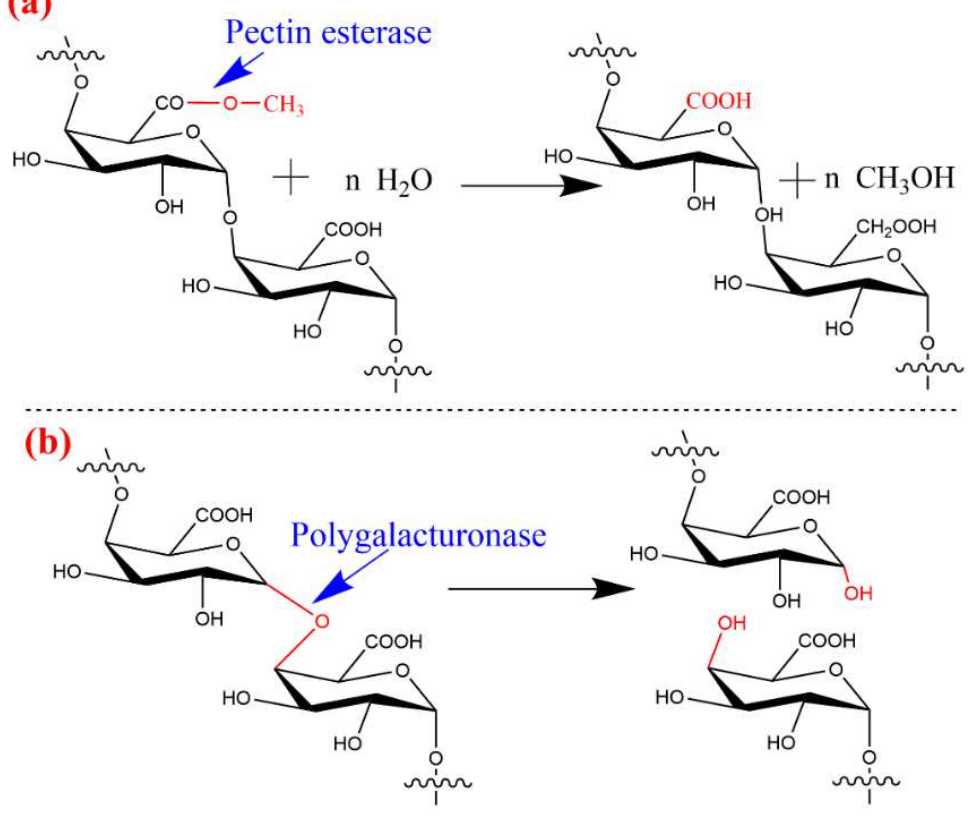

Fig 7. Pectinase interaction model: (a) pectin esterase interaction model, (b) polygalacturonase interaction model

Xylan is one of the main components of hemicellulose, consisting of $\beta$-1,4-linked xylan pyranose residues (Polizeli et al. 2005). Xylanase, a complex enzyme, includes $\beta$-1,4-endoxylanase, $\beta-1,4-$ exoxylanase and $\beta$-xylosidase. Xylanase is a hydrolase that can degrade hemicellulose xylan to produce xylooligosaccharides and xylose, which can completely hydrolyze xylan, thereby releasing xylose monomers or oligomers (Beg et al. 2001). Figure 8 showed the typical structure of xylan in hemicellulose and the mode of action of xylanase (Pakarinen et al. 2012; Zhang et al. 2013a). Alkaline xylanase can effectively degrade xylan, which resulted in a significant decrease in hemicellulose content. This was consistent with the results of SEM morphology, component analysis.

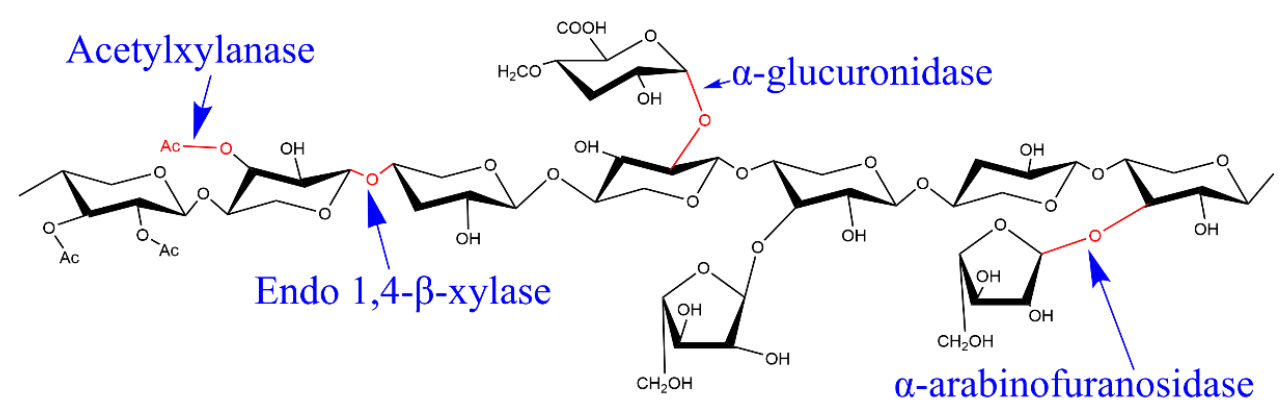

Fig 8. Typical structure of xylan in hemicellulose and xylanase interaction positions 


\subsection{Physical and mechanical properties}

The fineness and tenacity of the hemp fiber had a direct impact on the application range of the fiber. Figure 9 illustrated the fineness and tenacity of hemp fibers with different degumming processes. Compared with the buffer-treated fiber (2\#), the fineness of the fibers prepared by pectinase or xylanase (3\#, 4\#) were significantly improved, and the fineness was finer. The main reason was that the action of alkaline pectinase and alkaline xylanase broke the connection between the fibers, the fiber bundles changed from large to small, and the linear density of the fibers decreased. The synergistic effect between alkaline pectinase and alkaline xylanase reduced the number of bonding points between fibers, separated the fibers from each other, and reduced the number of fibers in the bundle, resulting in a decrease in linear density. The breaking point of the hemp technology bundle fiber was not the single fiber but the bonding point between the fibers. Therefore, the strength of hemp fiber was directly related to the linear density. The greater the linear density of the fiber, the more breaking points and the lower the breaking strength of the fiber. The number of bonding points was related to the content of non-cellulose in the fiber composition: the more non-cellulose content, the more fiber bonding points and the lower the fiber strength. Under the joint action of pectinase and xylanase, the prepared fiber had the lowest non-cellulose content and the highest strength. This phenomenon was consistent with the result of chemical composition analysis and FT-IR.

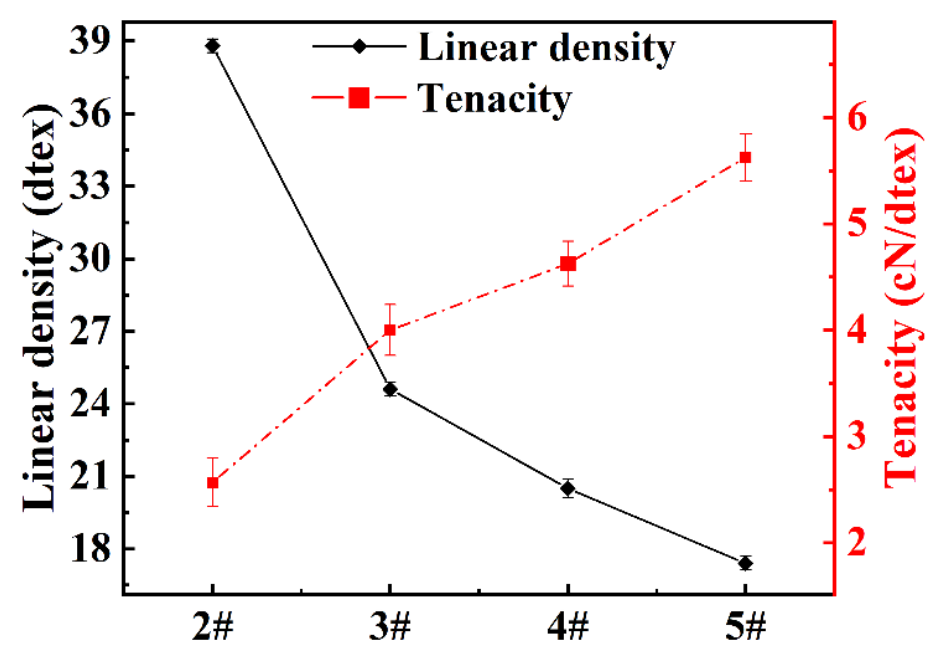

Fig 9. Linear density and tenacity of hemp fibers with different treatments: 2\# hemp treated with buffer solution, $3 \#$ hemp treated with alkaline pectinase solution, 4\# hemp treated with alkaline xylanase solution, $5 \#$ hemp treated with alkaline pectinase-xylanase solution

\subsection{Moisture sorption and water retention}

Generally, water retention value is affected by fiber composition and the swelling capacity and degree 

fibers treated in different ways. Compared with untreated hemp fiber, the water retention value of degummed hemp fibers was slightly enhanced. The water retention value of the fiber treated with alkaline pectinase- xylanase system (5\#) was about 1.7 times higher than that of raw hemp fiber, mainly due to the change of fiber surface morphology and chemical composition. After the removal of the gum substrate, the fiber structure became looser and deeper cracks appeared. There was more space among the fibers, which allowed extra water to penetrate the fibers.

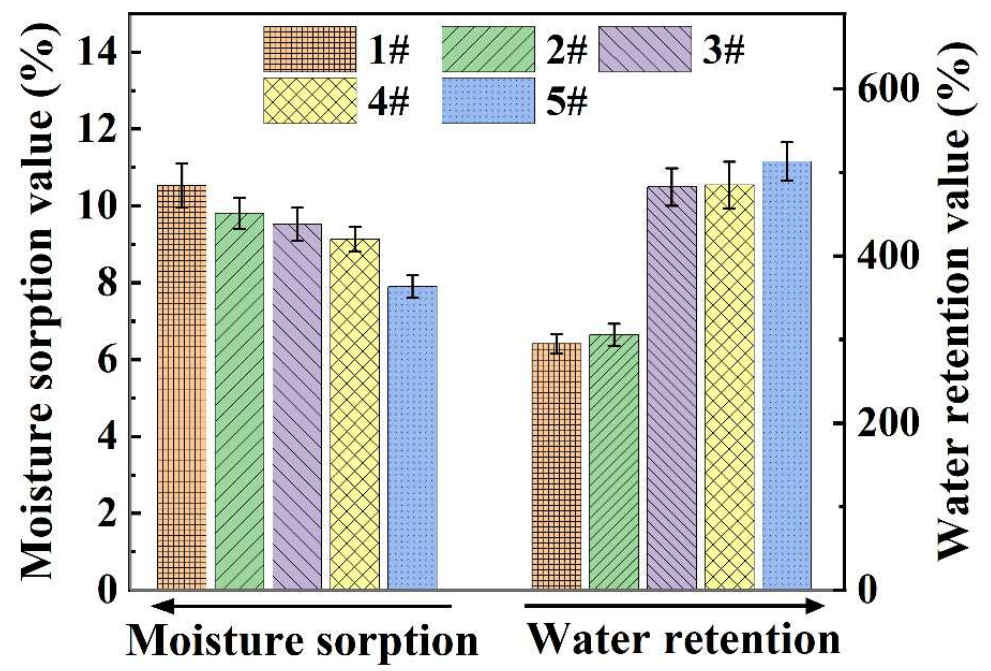

Fig 10. Moisture sorption and water retention of hemp fiber with different treatments: $1 \#$ raw hemp, 2\# hemp treated with buffer solution, $3 \#$ hemp treated with alkaline pectinase solution, $4 \#$ hemp treated with alkaline xylanase solution, $5 \#$ hemp treated with alkaline pectinase-xylanase solution In addition, apart from van der Waals forces and hydrogen bonds between cellulose and hemicellulose, hemicellulose and cellulose were not chemically connected (Sun et al. 2003). The content of lignin could affect the swelling capacity of fiber. Lignin, which wrapped around cellulose, had a compact molecular structure that made it hard for water molecules to penetrate. The water retention value in $3 \#$ and $4 \#$ had little difference, and it demonstrated that the situation of fiber looseness played an essential role in the water retention value. Compared with raw hemp, the moisture absorption value of treated fibers had a slight change. The raw hemp fiber (1\#) had the highest moisture absorption performance, mainly because it had a large amount of non-cellulose components, especially pectin and hemicellulose, and pectin and hemicellulose had abundant hydrophilic groups (Mwaikambo et al. 2002). As the content of non-cellulose in the fiber was removed, the moisture absorption of the fiber naturally decreased (Pejic et al. 2008). From the analysis, we can safely draw a conclusion that hemicellulose 
content was one of the main factors affecting moisture absorption performance, and this was consistent with the results of other previous studies (Milanovic et al. 2012).

\section{Conclusion}

The traditional chemical degumming processes use a lot of harmful chemicals, especially strong alkalis, which have caused serious challenges to the environment. It is urgent to call for the development of clean, water and energy conservation degumming. This research provided a greener and more ecofriendly hemp degumming process without strong alkali and strong acid. We have found that under mild conditions $\left(\mathrm{pH}=8.0, \mathrm{~T}=55^{\circ} \mathrm{C}\right)$, alkaline pectinase and alkaline xylanase could simultaneously exert better activity. It demonstrated that the two alkaline enzymes played a synergistic effect through degumming process, significantly removing pectin (up to $75 \%$ ) and hemicellulose (up to $40 \%$ ). The cellulose content of the obtained hemp fiber was about $79 \%$, and the surface of the fiber was smooth. The results showed that the alkaline pectinase-xylanase system could effectively remove non-cellulose components and significantly improve the properties of hemp fiber. The hemp fiber treated by the alkaline pectinasexylanase system had good water retention performance (513\%), moisture sorption ( $8.9 \%)$ and excellent mechanical properties (17.4 dtex, $5.62 \mathrm{cN} / \mathrm{dtex}$,). It was finer and had a lower content of gum components, which had greater application prospects in the textile industry and composite material industry. The alkaline pectinase-xylanase system provides a referable degumming solution for other bast fibers.

\section{Acknowledgements}

This work was supported by the Fundamental Research Funds for the Central Universities (Grant numbers 2232020G-01 and 2232020A-07). The authors gratefully acknowledge the financial support for the research.

\section{Compliance with ethical standards}

\section{Conflicts of interests}

The authors declare that they have no conflict of interest. This article does not contain any studies with human participants or animals performed by any of the authors. Informed consent was obtained from all individual participants included in the study.

\section{References}

Basu S, Saha MN, Chattopadhyay D, Chakrabarti K (2009) Degumming and characterization of ramie fibre using pectate lyase from immobilized Bacillus pumilus DKS1. Lett Appl Microbiol 48:593- 
Batog J, Przepiera A (2011) Enzymatic processing of lignin in the production of lignocellulosic composites. Cell Chem Technol 45:503-505

Beg Q, Kapoor M, Mahajan L, Hoondal G (2001) Microbial xylanases and their industrial applications: a review. Appl Microbiol Biotechnol 56:326-338

Chen FL, Shen YL, Liu SS, Yang YD, Wang LL (2021) Water footprint of textile industry: a case study of China. Environ Eng Manage J 20:237-245

El Achaby M, El Miri N, Hannache H, Gmouh S, Trabadelo V, Aboulkas A, Ben Youcef H (2018) Cellulose nanocrystals from Miscanthus fibers: insights into rheological, physico-chemical properties and polymer reinforcing ability. Cellulose 25:6603-6619

Fan P, He F, Yang Y, Ao M, Ouyang J, Liu Y, Yu L (2015) In-situ microbial degumming technology with Bacillus sp. HG-28 for industrial production of ramie fibers. Biochem Eng J 97:50-58

Fang G, Chen H-g, Chen A-q, Mao K-w, Wang Q (2017) An Efficient Method of Bio-Chemical Combined Treatment for Obtaining High-Quality Hemp Fiber. Bioresources 12:13

French AD (2014) Idealized powder diffraction patterns for cellulose polymorphs. Cellulose 21:885-896

Gorshkova T et al. (2012) Plant Fiber Formation: State of the Art, Recent and Expected Progress, and Open Questions. Crit Rev Plant Sci 31:201-228

Gorshkova T, Morvan C (2006) Secondary cell-wall assembly in flax phloem fibres: role of galactans. Planta 223:149-158

Islam S, Bhat G (2019) Environmentally-friendly thermal and acoustic insulation materials from recycled textiles. J Environ Manage 251:109536

Jena B, Das BP, Khandual A, Sahu S, Behera L (2015) Ecofriendly processing of textiles. Mater Today: Proc 2:1776-1791

Jinqiu Z, Jianchun Z (2010) Effect of Refined Processing on the Physical and Chemical Properties of Hemp Bast Fibers. Text Res J 80:744-753

Kashyap DR, Vohra PK, Chopra S, Tewari R (2001) Applications of pectinases in the commercial sector: a review. Bioresour Technol 77:215-227

Kassab Z, Boujemaoui A, Ben Youcef H, Hajlane A, Hannache H, El Achaby M (2019) Production of cellulose nanofibrils from alfa fibers and its nanoreinforcement potential in polymer nanocomposites. Cellulose 26:9567-9581

Khalili S, Akin DE, Pettersson B, Henriksson G (2002) Fibernodes in flax and other bast fibers. J Appl Bot-Angew Bot 76:133-138

Kozlowski R, Batog J, Konczewicz W, Mackiewicz-Talarczyk M, Muzyczek M, Sedelnik N, Tanska B (2006) Enzymes in Bast Fibrous Plant Processing. Biotechnol Lett 28:761-765

Li P et al. (2021) Visual analysis of the morphological features and polysaccharide distribution of raw ramie and their influence on degumming. Cellulose 28:1203-1218

Liu L, Xiang Y, Zhang R, Li B, Yu J (2019) Effect of NaClO dosage on the structure of degummed hemp fibers by 2,2,6, 6-tetramethyl-1-piperidinyloxy-laccase degumming. Text Res J 89:76-86

Liu L, Xiang YP, Zhang RY, Li B, Yu JY, Fang B (2017) TEMPO-media Oxidation Combined with Laccase for Effective Degumming Pretreatment of Hemp Fibers. Bioresources 12:8848-8861

Ma G, Zhu W, Liu Y (2016) QM/MM studies on the calcium-assisted $\beta$-elimination mechanism of pectate lyase from bacillus subtilis. Proteins: Struct Funct Bioinf 84:1606-1615

Meng C, Hu J, Yu C, Sun F (2019) Evaluation of the mild $\operatorname{Mg}(\mathrm{OH}) 2-\mathrm{AQ}$ aided alkaline oxidation degumming process of ramie fiber at an industrial scale. Ind Crop Prod 137:694-701 
Meng C, Yang J, Zhang B, Yu C (2018) Rapid and energy-saving preparation of ramie fiber in TEMPOmediated selective oxidation system. Ind Crop Prod 126:143-150

Milanovic J, Kostic M, Milanovic P, Skundric P (2012) Influence of TEMPO-Mediated Oxidation on Properties of Hemp Fibers. Ind Eng Chem Res 51:9750-9759

Mohanty AK, Misra M, Hinrichsen G (2000) Biofibres, biodegradable polymers and biocomposites: An overview. Macromol Mater Eng 276-277:1-24

Mwaikambo LY, Ansell MP (2002) Chemical modification of hemp, sisal, jute, and kapok fibers by alkalization. J Appl Polym Sci 84:2222-2234

Nie S, Zhang K, Lin X, Zhang C, Yan D, Liang H, Wang S (2018) Enzymatic pretreatment for the improvement of dispersion and film properties of cellulose nanofibrils. Carbohydr Polym 181:11361142

Nishiyama Y, Sugiyama J, Chanzy H, Langan P (2003) Crystal Structure and Hydrogen Bonding System in Cellulose I $\alpha$ from Synchrotron X-ray and Neutron Fiber Diffraction. J Am Chem Soc 125:1430014306

Pakarinen A, Zhang J, Brock T, Maijala P, Viikari L (2012) Enzymatic accessibility of fiber hemp is enhanced by enzymatic or chemical removal of pectin. Bioresour Technol 107:275-281

Pejic BM, Kostic MM, Skundric PD, Praskalo JZ (2008) The effects of hemicelluloses and lignin removal on water uptake behavior of hemp fibers. Bioresour Technol 99:7152-7159

Polizeli MLTM, Rizzatti ACS, Monti R, Terenzi HF, Jorge JA, Amorim DS (2005) Xylanases from fungi: properties and industrial applications. Appl Microbiol Biotechnol 67:577-591

$\mathrm{Qu} \mathrm{Y}$ et al. (2020a) High-efficiency and recyclability of ramie degumming catalyzed by $\mathrm{FeCl} 3$ in organic solvent. Carbohydr Polym 239:116250

Qu Y, Yin W, Zhang R, Zhao S, Liu L, Yu J (2020b) Isolation and characterization of cellulosic fibers from ramie using organosolv degumming process. Cellulose 27:1225-1237

Qu Y, Zhao S, Shi Z, Zhang R, Liu L, Ji F, Yu J (2020c) High-efficiency organosolv degumming of ramie fiber by autocatalysis of high-boiling alcohols: an evaluation study of solvents. Cellulose 27:42714285

Ranalli P, Venturi G (2004) Hemp as a raw material for industrial applications. Euphytica 140:1-6

Sadrmanesh V, Chen Y (2019) Bast fibres: structure, processing, properties, and applications. Int Mater Rev 64:381-406

Sain M, Panthapulakkal S (2006) Bioprocess preparation of wheat straw fibers and their characterization. Ind Crop Prod 23:1-8

Saito T, Isogai A (2004) TEMPO-Mediated Oxidation of Native Cellulose. The Effect of Oxidation Conditions on Chemical and Crystal Structures of the Water-Insoluble Fractions. Biomacromolecules 5:1983-1989

Schäfer T, Honermeier B (2006) Effect of sowing date and plant density on the cell morphology of hemp (Cannabis sativa L.). Ind Crop Prod 23:88-98

Sun R, Sun XF, Tomkinson J (2003) Hemicelluloses and Their Derivatives. In: Hemicelluloses: Science and Technology, vol 864. ACS Symposium Series, vol 864. American Chemical Society, pp $2-22$.

Terzopoulou ZN, Papageorgiou GZ, Papadopoulou E, Athanassiadou E, Alexopoulou E, Bikiaris DN (2015) Green composites prepared from aliphatic polyesters and bast fibers. Ind Crop Prod 68:6079

Valladares Juárez AG, Dreyer J, Göpel PK, Koschke N, Frank D, Märkl H, Müller R (2009) 
Characterisation of a new thermoalkaliphilic bacterium for the production of high-quality hemp fibres, Geobacillus thermoglucosidasius strain PB94A. Appl Microbiol Biotechnol 83:521-527

Wang HM, Postle R, Kessler RW, Kessler W (2003) Removing Pectin and Lignin During Chemical Processing of Hemp for Textile Applications. Text Res J 73:664-669

Xiao Z, Wang S, Bergeron H, Zhang J, Lau PCK (2008) A flax-retting endopolygalacturonase-encoding gene from Rhizopus oryzae. Antonie van Leeuwenhoek 94:563

Yeping X, Jianyong Y, Liu L, Ruiyun Z, Yongshuai Q, Miaolei J (2019a) The chemo-enzymatic modification and degumming of hemp fiber by the laccase-2,2,6,6-tetramethylpiperidine-1-oxyl radical-hemicellulase system and physico-chemical properties of the products. Text Res J 89:24332443

Yeping X, Liu L, Ruiyun Z, Jianyong Y, Bin F, Feng J, Miaolei J (2019b) Circulating solution for the degumming and modification of hemp fiber by the laccase-2,2,6,6-tetramethylpiperidine-1-oxyl radical-hemicellulase system. Text Res J 89:4339-4348

Zhang J, Pakarinen A, Viikari L (2013a) Synergy between cellulases and pectinases in the hydrolysis of hemp. Bioresour Technol 129:302-307

Zhang Q, Yan S (2013b) Degumming of ramie bast fibers by Ca2+-activated composite enzyme. J Text Inst 104:78-83

Zheng Y, Zhang Z, Luo Z-W (1988) Optimizing the Complex Formulation of Boiling-off Liquor for Ramie Chemical Degumming. Text Res J 58:663-666

Zykwinska A, Thibault J-F, Ralet M-C (2008) Competitive binding of pectin and xyloglucan with primary cell wall cellulose. Carbohydr Polym 74:957-961 